Check for updates

Cite this: RSC Adv., 2017, 7, 31180

Received 10th April 2017

Accepted 12th June 2017

DOI: $10.1039 / \mathrm{c} 7 \mathrm{ra0} 4049 \mathrm{k}$

rsc.li/rsc-advances

\section{Enhanced fuel ethanol production from rice straw hydrolysate by an inhibitor-tolerant mutant strain of Scheffersomyces stipitis}

\author{
Kedong Ma, (D) $\dagger^{\star a b}$ Mingxiong He, ${ }^{D} \dagger^{\mathrm{b}}$ Huiyan You, ${ }^{\mathrm{a}}$ Liwei Pan, ${ }^{a}$ Guoquan $\mathrm{Hu},{ }^{\mathrm{b}}$ \\ Yubo Cuic and Toshinari Maeda iD d
}

\begin{abstract}
The aim of the present study was to develop an inhibitor-tolerant strain of Scheffersomyces stipitis and establish an efficient ethanol fermentation process for cost-effective ethanol production from lignocellulosic biomass. By a strategy of three successive rounds of UV mutagenesis following adaptation, we isolated a S. stipitis mutant with improved tolerance against ethanol and inhibitors in the form of acetic acid, furfural and vanillin. The mutant strain exhibited excellent ethanol fermentation performance; both the xylose and glucose consumption rate and ethanol productivity were almost two times higher than the parental strain in batch fermentation. To overcome the issue of product inhibition and carbon catabolite repression (CCR) effect, the membrane integrated continuous fermentation system was employed. The maximum ethanol titer of $43.2 \mathrm{~g} \mathrm{l}^{-1}$ and productivity of $2.16 \mathrm{~g} \mathrm{l}^{-1} \mathrm{~h}^{-1}$ was achieved at a dilution rate of $0.05 \mathrm{~h}^{-1}$, higher than the relevant studies ever reported. These results suggested the novel process of cell recycling continuous fermentation using $S$. stipitis mutant has great potential for commercial ethanol production from lignocelluloses-based biomass.
\end{abstract}

\section{Introduction}

Lignocellulosic biomass is considered as a promising renewable resource for second generation fuel ethanol production due to its advantages of low cost, abundance and renewability. ${ }^{1-3}$ The carbohydrate fraction of lignocellulose is composed of monosaccharides such as hexose (glucose, cellobiose) and pentose (xylose, arabinose) sugars. ${ }^{4}$ The hexose sugars can be converted rapidly to ethanol by the yeast Saccharomyces cerevisiae or bacterium Zymomonas mobilis, but the pentose sugars in terms of xylose and arabinose cannot be metabolized naturally., Because xylose is the second most abundant fermentable sugar, conversion of both hexose and pentose sugars to fuel ethanol using an appropriate ethanol producer could theoretically increase the total ethanol yield by $25 \% .^{7,8}$ Therefore, the xylosefermenting yeast utilizing both hexose and pentose sugars is

${ }^{a}$ College of Environmental and Chemical Engineering, Dalian University, Dalian 116622, PR China.E-mail: makedongdl@yahoo.co.jp

${ }^{b}$ Key Laboratory of Development and Application of Rural Renewable Energy, Ministry of Agriculture, Biomass Energy Technology Research Centre, Biogas Institute of Ministry of Agriculture, Chengdu 610041, PR China

'Department of Environmental Science and Technology, Dalian Nationalities University, Dalian 116600, PR China

${ }^{d}$ Department of Biological Functions Engineering, Graduate School of Life Science and Systems Engineering, Kyushu Institute of Technology, 2-4 Hibikino, Wakamatsu-ku, Kitakyushu 808-0196, Japan

$\dagger$ Two authors equally contributed to this work and should be considered co-first author. necessary for the economic production of lignocellulosic ethanol. ${ }^{4,9}$

Scheffersomyces stipitis (formerly known as Pichia stipitis) is capable of fermenting a wide range of sugars to ethanol. ${ }^{\mathbf{1 0 , 1 1}}$ Among the naturally occurring xylose-fermenting yeasts such as Candida shehatae and Pachysolen tannophilus, S. stipitis is considered an excellent candidate for ethanol production from lignocelluloses since it ferments xylose with a high ethanol yield and has no absolute vitamin requirements during the fermentation. ${ }^{12-14}$ However, the ethanol productivity of the xylosefermenting yeast on glucose or xylose is much lower than that obtained from $S$. cerevisiae when cultivated on glucose. ${ }^{15,16}$ In addition, the xylose-fermenting yeasts generally suffer from hexose repression, end-product of ethanol and toxins formed during pretreatment of lignocellulosic biomass such as acetic acid, furans and phenolic compounds, which can greatly inhibit yeast growth, viability and ethanol production. ${ }^{17-22}$ Specially, some studies reveal the inhibitory effect of these by-products is much more severe for xylose fermentation than for glucose fermentation, preventing efficient co-fermentation of lignocellulosic hydrolysates. ${ }^{23,24}$ To eliminate the toxic effect, a step of washing and detoxification has been suggested to remove inhibitors before fermentation while it would significantly increases the fuel ethanol production cost. ${ }^{24}$ Therefore, from the economic viewpoint, the development of inhibitor-tolerant $S$. stipitis strain is essential to achieve cost-effective conversion of lignocelluloses to ethanol. 
The approach of evolutionary engineering is considered to be useful for acquiring microorganism with desirable phenotypes, such as an expanded substrate range, increased stress tolerance, and efficient substrate utilization. ${ }^{25}$ Nigam $^{20}$ reported an adapted $S$. stipitis strain fermenting the acid prehydrolysate to ethanol at lower initial $\mathrm{pH}$ values. Bajwa et al. ${ }^{22}$ obtained a $S$. stipitis strain with improved tolerance to inhibitors in hardwood spent sulfite liquor, and Hughes et al. ${ }^{26}$ isolated a strain capable of growing anaerobically on xylose/glucose substrate with high ethanol production after UV mutagenesis. Except for the specific stress against capability, these mutant strains also produced higher ethanol titer and productivity than the parent strains under the stress conditions. Moreover, Watanabe et al. ${ }^{21}$ yielded an ethanol-tolerant $S$. stipitis strain PET41 by repeated exposure a UV induced strain PFX 58 to increasing ethanol concentrations. PET41 presented higher ethanol tolerance and ethanol production capability than PFX 58, thus suggested that a combination of UV mutagenesis and adaption might be a useful strategy to acquire yeast strain with constitutively highlevel tolerance towards inhibitors and improved ethanol production ability, which would absolutely be preferable for industrial applications.

In the present study, we isolated a mutant strain of $S$. stipitis using a strategy of UV induced random mutagenesis following repeated exposure to increasing ethanol or/and clotrimazole (CTZ) concentrations. It had been reported that CTZ-resistant mutant of sake yeast showed enhanced ethanol production rate and produced higher amounts of alcohol than the parent strain during the sake fermentation. ${ }^{27}$ On the other hand, CTZresistant mutant displayed pleiotropic drug resistance (PDR) phenotypes. They were resistant to not only a number of azole fungicides but also a wide range of unrelated cytotoxic compounds including cycloheximide, cerulenin, 4-nitroquinoline- $N$-oxide (4-NQO), oligomycin and anionic drugs such as reveromycin A and acetic acid. ${ }^{27}$ Therefore, the mutant isolated by means of UV mutagenesis following adaption in CTZ was expected to acquire the improved fermentative activity and constitutive tolerance to major fermentative inhibitors in terms of acetic acid, furan and vanillin. The ethanol fermentation performance of selected mutant and parent strain in inhibitors absent and present model substrate was examined. In addition, the carbon catabolite repression (CCR) effect on the mutant was analyzed under different glucose/xylose ratios in model substrate as well. Furthermore, a continuous fermentation with a cell recycle system was adopted to examine the possibility of improving fuel ethanol production from lignocellulosic hydrolysate without any detoxification. To the best of our knowledge, there are few reports with regard to membrane cell-recycle techniques for the continuous fermentation of ethanol from sugar mixture of hexose and pentose derived from lignocellulosic hydrolysate using $S$. stipitis.

\section{Materials and methods}

\subsection{Microorganism and cultivation}

Scheffersomyces stipitis (formerly Pichia stipitis) NBRC1687 wild type (WT) strain was purchased from the culture collection of the NITE Biological Resource Center (NBRC, Japan). S. stipitis strain MA301 was obtained by UV mutagenesis of the WT followed by adaptation.

S. stipitis WT and mutant strains were maintained individually on YPX agar plates at $4{ }^{\circ} \mathrm{C}$ and subcultured at monthly intervals. YPX agar consisted of $10 \mathrm{~g} \mathrm{l}^{-1}$ yeast extract, $20 \mathrm{~g} \mathrm{l}^{-1}$ peptone, $20 \mathrm{~g} \mathrm{l}^{-1}$ xylose and $15 \mathrm{~g} \mathrm{l}^{-1}$ agar. For inoculation, one loop of cells from an isolated colony on YPX agar plate was transferred to $50 \mathrm{ml}$ of YPX broth in a $250 \mathrm{ml}$ Erlenmeyer flask and incubated for $24 \mathrm{~h}$ at $30{ }^{\circ} \mathrm{C}$ with agitation at $200 \mathrm{rpm}$ on a rotary shaker.

\subsection{UV mutation and adaptation}

Yeast strains cultivated in YPX medium with shaking for $24 \mathrm{~h}$ were collected and washed twice, then diluted by sterilized water to reach $\mathrm{OD}_{600}$ around 1.0. The mixture was transferred to plastic Petri dishes and exposed to UV light at a distance of $50 \mathrm{~cm}$ for $30 \mathrm{~s} .100 \mu \mathrm{l}$ of the UV-irradiated mixture was spread on YPX agar plates containing $30 \mathrm{~g} \mathrm{l}^{-1}$ ethanol then incubated at $28{ }^{\circ} \mathrm{C}$ for 7 days. The larger colonies were picked up and growing them in YPX broth containing $50 \mathrm{~g} \mathrm{l}^{-1}$ ethanol. Any surviving microorganisms were then transferred into a fresh adaptation medium containing increasing concentrations of ethanol (30, 40, 50 and $60 \mathrm{~g} \mathrm{l}^{-1}$ ). The mutants with improved ethanol tolerance were subjected to ethanol fermentation, and the most efficient ethanol producer was designated as the first generation mutant. In the second round of mutagenesis, the first generation mutant was exposed to UV light as described above, then spread on YPX agar plate with $20 \mathrm{mg} \mathrm{l}^{-1}$ of clotrimazole (CTZ) and incubated at $28{ }^{\circ} \mathrm{C}$ for 7 days. The colonies appeared were selected and cultured in YPX broth with $20 \mathrm{mg} \mathrm{l}^{-1} \mathrm{CTZ}$ first, then sequentially transferred to YPX broth containing increasing concentration of CTZ $\left(20,30,40\right.$ and $\left.50 \mathrm{mg} \mathrm{l}^{-1}\right)$. The mutants growing in YPX broth with higher CTZ concentration were subjected to ethanol fermentation, and the highest ethanol producer was designated as the second generation mutant. In the third round of mutagenesis, the second generation mutant was exposed to UV light then spread on YPX agar plate comprising $40 \mathrm{mg} \mathrm{l}^{-1} \mathrm{CTZ}$. After incubation for 7 days, the colonies were collected and inoculated in YPX broth with $40 \mathrm{mg}$ $\mathrm{l}^{-1} \mathrm{CTZ}$ and $60 \mathrm{~g} \mathrm{l}^{-1}$ ethanol. The adaption was performed with the ethanol concentration in YPX broth gradually increased to $70 \mathrm{~g} \mathrm{l}^{-1}$ and $80 \mathrm{~g} \mathrm{l}^{-1}$. The mutants obtained from YPX broth containing $40 \mathrm{mg} \mathrm{l}^{-1} \mathrm{CTZ}$ and $80 \mathrm{~g} \mathrm{l}^{-1}$ ethanol were subjected to ethanol fermentation, and the highest ethanol producer was the third generation mutant and named as S. stipitis MA301.

\subsection{Preparation of rice straw hydrolysate (RSH)}

The rice straw was collected from a local farm near Zhuanghe (Dalian, China) in fall 2015. The raw straw material was milled into a size between $0.5 \mathrm{~mm}$ to $0.9 \mathrm{~mm}$ and stored in air tight container for further experiments. Dilute sulfuric acid $(1 \%, \mathrm{w} / \mathrm{v})$ pretreatment and enzymatic hydrolysis of RS was carried out by the procedure described previously. ${ }^{1}$ The $\mathrm{RSH}$ after concentration normally contained $59.3 \mathrm{~g} \mathrm{l}^{-1}$ of glucose, $43.7 \mathrm{~g} \mathrm{l}^{-1}$ of xylose 
and $4.7 \mathrm{~g} \mathrm{l}^{-1}$ arabinose with inhibitors including $2.01 \mathrm{~g} \mathrm{l}^{-1}$ of acetic acid, $0.87 \mathrm{~g} \mathrm{l}^{-1}$ of furfural and $0.96 \mathrm{~g} \mathrm{l}^{-1}$ of phenolics.

\subsection{Fermentation}

2.4.1. Batch fermentation. The batch fermentation was performed in a 31 bioreactor (BIOSTAT B., B. Braun Biotech International $\mathrm{GmbH}$, Melsungen, Germany) containing $0.9 \mathrm{l}$ of model fermentation medium inoculated with $0.1 \mathrm{l}$ of seed culture. Fermentation was maintained at $30{ }^{\circ} \mathrm{C}$, agitation rate of $700 \mathrm{rpm}$ and aeration rate was $0.1 \mathrm{l} \mathrm{min}^{-1}$. The $\mathrm{pH}$ of the culture was monitored but not regulated. The model fermentation medium was composed of $100 \mathrm{~g} \mathrm{l}^{-1}$ sugar, $10 \mathrm{~g} \mathrm{l}^{-1}$ yeast extract, $20 \mathrm{~g} \mathrm{l}^{-1}$ peptone. Antifoaming agent $(0.01 \% \mathrm{v} / \mathrm{v})$ Antifoam SI (Wako Pure Chemical Industries, Ltd., Osaka, Japan) was added to fermentation medium during the experiment.

To evaluate the sole sugar or mixed sugar conversion rate of wild type strain and mutant strain, the initial sugars in model medium were $100 \mathrm{~g} \mathrm{l}^{-1}$ glucose or $100 \mathrm{~g} \mathrm{l}^{-1}$ xylose or $100 \mathrm{~g} \mathrm{l}^{-1}$ mixed sugar (glucose/xylose $=1: 1$ ), respectively. In the experiments of examining the influence of glucose and xylose proportion in the sugar mixtures on ethanol production of mutant, the medium were prepared as follows: $80 \mathrm{~g} \mathrm{l}^{-1}$ glucose/ $20 \mathrm{~g} \mathrm{l}^{-1}$ xylose (G80X20), $60 \mathrm{~g} \mathrm{l}^{-1}$ glucose/40 $\mathrm{g} \mathrm{l}^{-1}$ xylose (G60X40), $40 \mathrm{~g} \mathrm{l}^{-1}$ glucose/60 $\mathrm{g} \mathrm{l}^{-1}$ xylose (G40X60) and $20 \mathrm{~g} \mathrm{l}^{-1}$ glucose/80 $\mathrm{g} \mathrm{l}^{-1}$ xylose (G20X80). To investigate the effects of inhibitors on ethanol production, acetic acid $\left(0.5-3.5 \mathrm{~g} \mathrm{l}^{-1}\right)$, furfural $\left(0.5-4.0 \mathrm{~g} \mathrm{l}^{-1}\right)$, and vanillin (0.5-1.5 $\left.\mathrm{g} \mathrm{l}^{-1}\right)$ was individually added in model medium. The initial $\mathrm{pH}$ of each medium was set at 5.0. The fermentation without inhibitors was also carried out as a control.

2.4.2. Continuous fermentation. A hollow-fibre microfiltration module (MICROZA PSP 103, Asahi Kasei, Tokyo, Japan; filtration area: $0.17 \mathrm{~m}^{2}$, fibre diameter: $0.7 \mathrm{~mm}$, pore size: $0.1 \mu \mathrm{m}$ ) was used for cell recycling during fermentation. Before use, the module was soaked in $70 \%$ ethanol for $24 \mathrm{~h}$, and then washed with sterile deionised water to adjust $\mathrm{pH}$ to 7.0. The continuous fermentation was performed as described in our previous study. ${ }^{28}$ Briefly, the fermentation was carried out in a hollow-fibre microfiltration module integrated $3 \mathrm{l}$ jar fermentor with $1 \mathrm{l}$ working volume of model medium or RSH containing $100 \mathrm{~g} \mathrm{l}^{-1}$ reducing sugar. The fermentation was initially operated in batch mode at $30{ }^{\circ} \mathrm{C}$, agitation speed of $700 \mathrm{rpm}$, and aeration rate of $0.1 \mathrm{l} \mathrm{min}^{-1}$. After sugar complete depletion, the continuous fermentation was started under the same condition. During the fermentation, the working volume in the bioreactor was maintained at $1 \mathrm{l}$ by feeding the fresh model medium or RSH. The samples were taken aseptically every $6 \mathrm{~h}$ for analysis. The continuous fermentation without cell recycling system was used as control.

To evaluate the influence of dilution rate $(D)$ on ethanol production, dilution rate of $0.03 \mathrm{~h}^{-1}, 0.05 \mathrm{~h}^{-1}, 0.10 \mathrm{~h}^{-1}$ and 0.15 $\mathrm{h}^{-1}$ was used, respectively.

\subsection{Analytical methods}

Glucose, xylose, arabinose, acetic acid, ethanol, hydroxymethyl furfural/HMF and furfural were analyzed on an Agilent 1200
HPLC system (Agilent, Palo Alto, CA, USA). with an Aminex HPX$87 \mathrm{H}$ column (300 $\mathrm{mm} \times 7.8 \mathrm{~mm}$, Bio-Rad, Richmond, CA, USA) at $45{ }^{\circ} \mathrm{C}$ with $0.6 \mathrm{ml} \mathrm{min}{ }^{-1}$ eluent of $5 \mathrm{mM}$ sulfuric acid as the mobile phase. The total concentrations of phenolics were measured based on the Folin and Ciocalteu's assay. ${ }^{29}$ Cell growth was determined by measuring the optical density at $600 \mathrm{~nm}$ and correlated to dry weight curve.

\section{Results and discussion}

\subsection{Isolation of ethanol and inhibitor tolerant $S$. stipitis mutant}

Inhibitor-tolerant yeast strain capable of fermenting all the sugars in non-detoxified lignocellulosic hydrolysates was absolutely required for efficient bioethanol production. A number of $S$. stipitis mutants with desirable phenotypes had been isolated by different selection methods such as UV mutagenesis and continuous adaption. In the present work, a strategy of UV mutagenesis following adaption was used to develop $S$. stipitis mutant with improved ethanol and inhibitor tolerance in addition to excellent ethanol fermentation performance. Wide type strain of $S$. stipitis NBRC1687 was subjected to three rounds of UV mutagenesis following adaption. After the first round of mutagenesis, 28 colonies that grew larger than wild type colonies on YPX $30 \mathrm{~g} \mathrm{l}^{-1}$ ethanol plate were selected. Five of these colonies could survive in YPX $60 \mathrm{~g} \mathrm{l}^{-1}$ ethanol broth and showed similar ethanol production pattern, which were more efficient than the parental. Further mutagenesis of the first generation mutants followed by adaption resulted in the isolation of two second generation mutants. Two of five mutants were lost when CTZ concentration increased to $20 \mathrm{mg} \mathrm{l}^{-1}$ and $30 \mathrm{mg} \mathrm{l}^{-1}$, and one mutant could tolerate and remain viable in YPX $40 \mathrm{mg} \mathrm{l}^{-1}$ CTZ broth but the ethanol productivity was unideal compared to the other two survivors (data not shown). The second generation mutants were subjected to UV mutagenesis followed by adaption. Both of mutants were capable of growing in YPX broth containing $40 \mathrm{mg} \mathrm{l}^{-1} \mathrm{CTZ}$ and $80 \mathrm{~g} \mathrm{l}^{-1}$ ethanol, while one mutant showed rapid growth and slight higher ethanol production capability than the other one, thus was chosen and designated as $S$. stipitis MA301 for the further study.

\subsection{Fermentation on model medium}

The profile of sugar consumption and ethanol fermentation of S. stipitis MA301 in sole sugar and mixed sugars was examined and compared with parent strain using model fermentation medium. In the case of fermentation using sole sugar, it was found that $S$. stipitis MA301 used glucose and xylose at a faster rate compared to the parental (Table 1, Fig. 1A and B). Around $100 \mathrm{~g} \mathrm{l}^{-1}$ of glucose and xylose was completely consumed after $24 \mathrm{~h}$ and $42 \mathrm{~h}$, resulted in ethanol titer of $48.31 \mathrm{~g} \mathrm{l}^{-1}$ and $46.36 \mathrm{~g}$ $\mathrm{l}^{-1}$, respectively. However, under the same condition, the parental strain required $48 \mathrm{~h}$ and $72 \mathrm{~h}$ to completely convert the glucose and xylose into $47.56 \mathrm{~g} \mathrm{l}^{-1}$ and $44.56 \mathrm{~g} \mathrm{l}^{-1}$ ethanol. The xylose and glucose consumption rate of the mutant was $2.09 \mathrm{~g}$ $\mathrm{l}^{-1} \mathrm{~h}^{-1}$ and $1.4 \mathrm{~g} \mathrm{l}^{-1} \mathrm{~h}^{-1}$, both were almost 2 times higher than those of parental. In addition to the increased glucose and 
Table 1 Fermentation performance of the parent and mutant strain in model medium with sole sugar and mixed sugar (G50/X50)

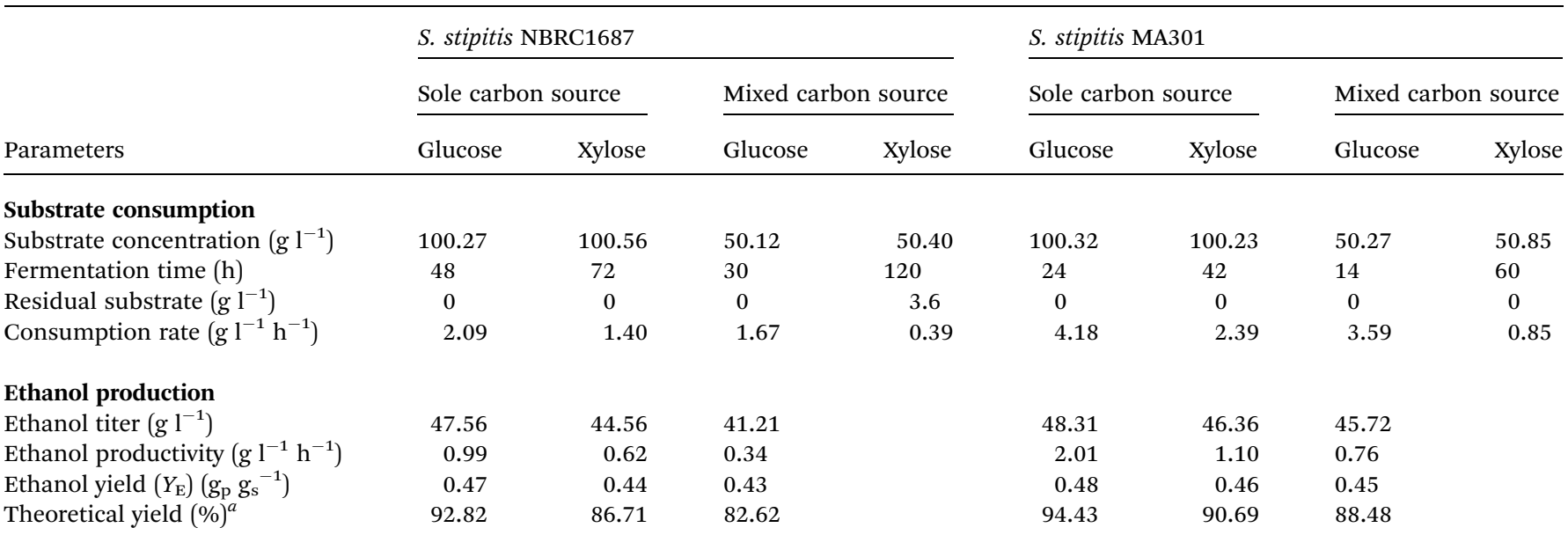

${ }^{a}$ Theoretical yield of ethanol from glucose or xylose is $0.51 \mathrm{~g}_{\mathrm{p}} \mathrm{g}_{\mathrm{s}}^{-1}$; \% theoretical yield is calculated as ethanol yield $\times 100$ divided by 0.51 .
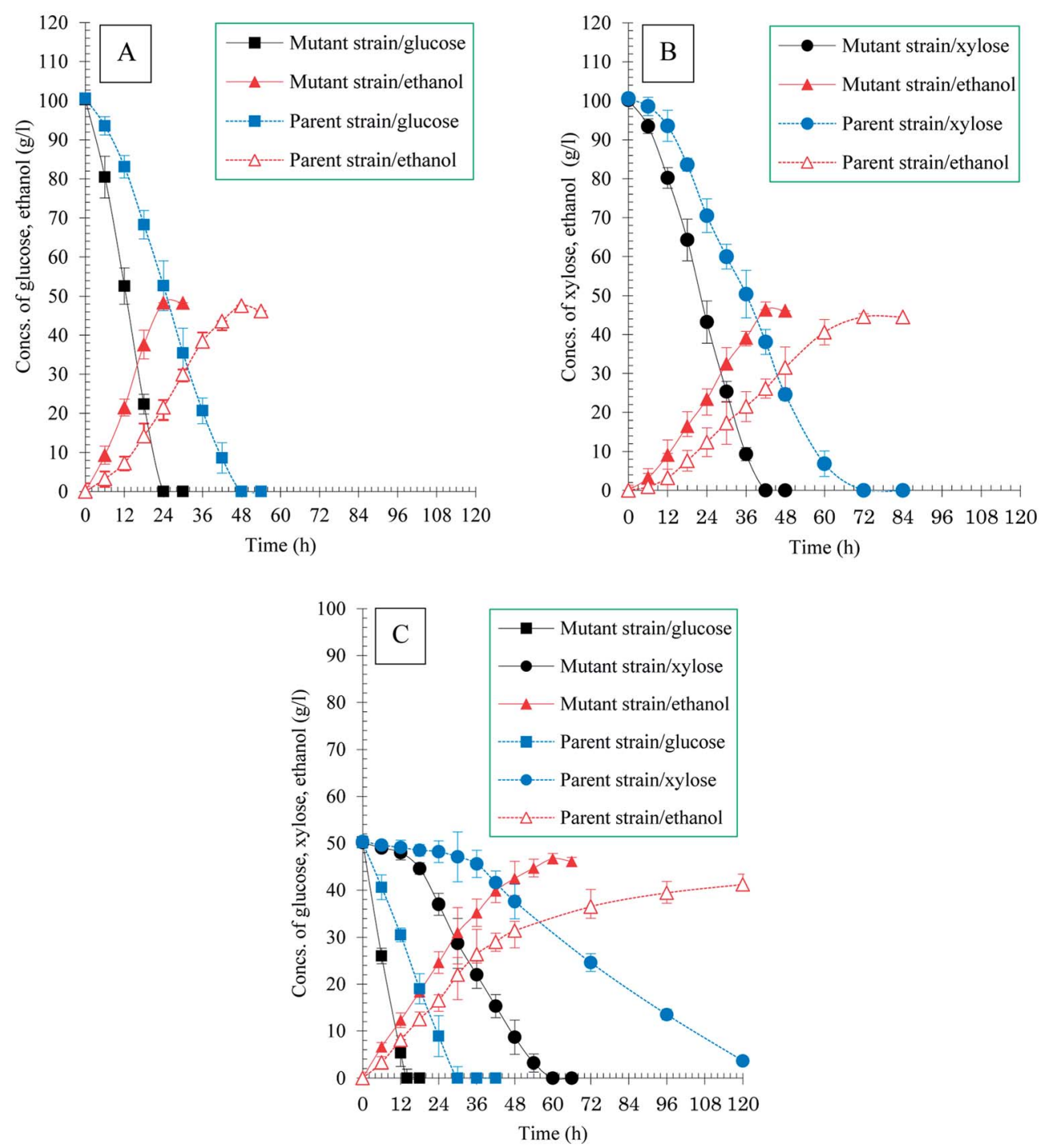

Fig. 1 The sugar consumption and ethanol production of the parent and mutant strain of S. stipitis in model medium. (A) Sole glucose, (B) sole xylose, (C) mixed sugar. The error bars in the figure indicate the standard deviations of three parallel replicates. 
xylose consumption rate, the ethanol productivity of the mutant was also improved by 2.0 and 1.8 fold compared to the parental strain, indicating that the approach of UV mutagenesis following adaption significantly improved the ethanol fermentation performance of $S$. stipitis strain.

In the case of fermentation in the mixture of glucose and xylose $(1: 1)$, the sugar utilization rates of both mutant and parent strain in co-fermentation were lower than that when glucose or xylose was used as sole substrate (Table 1, Fig. 1C). However, the mutant still exhibited efficient fermentation performance compared to the parental. S. stipitis MA301 completely consumed the sugars within $78 \mathrm{~h}$ resulting in $45.72 \mathrm{~g}$ $\mathrm{l}^{-1}$ ethanol, while for the parental, around $3.6 \mathrm{~g} \mathrm{l}^{-1}$ of xylose residual was detected in the medium after $120 \mathrm{~h}$ fermentation. As a result, the ethanol productivity $\left(0.34 \mathrm{~g} \mathrm{l}^{-1} \mathrm{~h}^{-1}\right)$ and the theoretical yield $\left(0.43 \mathrm{~g}_{\mathrm{p}} \mathrm{g}_{\mathrm{s}}^{-1}\right)$ were both lower than that of MA301 (0.78 $\mathrm{g} \mathrm{l}^{-1} \mathrm{~h}^{-1}$ and $\left.0.45 \mathrm{~g}_{\mathrm{p}} \mathrm{g}_{\mathrm{s}}{ }^{-1}\right)$. The lower sugar consumption rate in co-fermentation for both strains could be contributed to the glucose repression or carbon catabolite repression (CCR). As showed in Fig. 1C, xylose consumption commenced only when almost no glucose left in the medium.
The similar phenomenon was also observed in mixed sugar fermentation in G60X40 (Fig. 2B) and G40X60 (Fig. 2C) mixture. However, in the case of G80X20, the xylose utilization initiated when glucose concentration in medium was below to $10 \mathrm{~g} \mathrm{l}^{-1}$ (Fig. 2A). Furthermore, glucose and xylose was used simultaneously, with $92.35 \%$ of xylose consumed linearly at a constant consumption rate in the case of G20X80 (Fig. 2D). In these mixed sugar fermentations, complete utilization of glucose occurred within $20 \mathrm{~h}$ at similar consumption rates, while xylose utilization was quite different, indicating that the initial concentration of glucose was a key factor determining xylose utilization. In addition, CCR effect might be reduced by maintaining the glucose concentration at less than $20 \mathrm{~g} \mathrm{l}^{-1}$ in mixed sugars fermentation. Table 2 showed a summary of kinetic parameters of ethanol fermentation in mixtures with different glucose and xylose ratio. The maximum xylose consumption rate of $1.91 \mathrm{~g} \mathrm{l}^{-1} \mathrm{~h}^{-1}$ was achieved in the case of fermentation in G20X80 mixture, higher than that of G80X20, G60X40, and G40X60, at $0.69 \mathrm{~g} \mathrm{l}^{-1} \mathrm{~h}^{-1}, 0.81 \mathrm{~g} \mathrm{l}^{-1} \mathrm{~h}^{-1}$ and $0.84 \mathrm{~g} \mathrm{l}^{-1} \mathrm{~h}^{-1}$, respectively. In addition, the fermentation was finished after $30 \mathrm{~h}$ in G80X20 mixture, yielding the maximum ethanol titer,
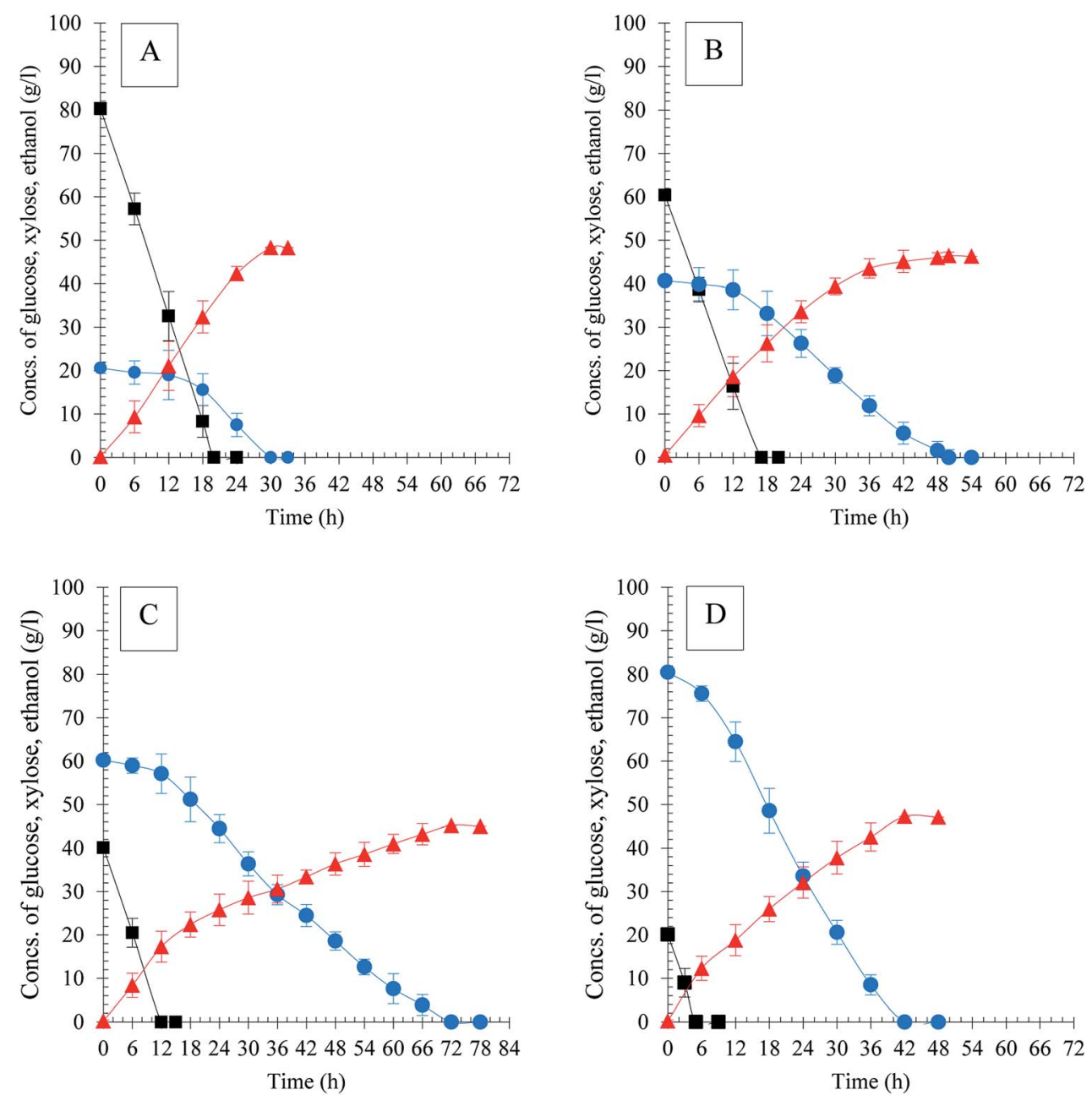

Fig. 2 Ethanol production of S. stipitis MA301 in model medium with different ratios of glucose and xylose. (A) G80X20; (B) G60X40; (C) G40X60;

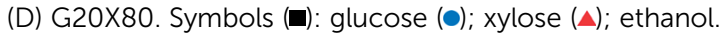


Table 2 Fermentation performance of mutant strain in model medium with various glucose/xylose ratios

Carbon source

Parameters

Xylose consumption time (h)

Glucose consumption time $(\mathrm{h})$

Glucose consumption rate $\left(\mathrm{g} \mathrm{l}^{-1} \mathrm{~h}^{-1}\right)$

Xylose consumption rate $\left(\mathrm{g} \mathrm{l}^{-1} \mathrm{~h}^{-1}\right)$

Xylose utilization ratio (\%)

Ethanol titer $\left(\mathrm{g} \mathrm{l}^{-1}\right)$

Ethanol productivity $\left(\mathrm{g} \mathrm{l}^{-1} \mathrm{~h}^{-1}\right)$

Ethanol yield $\left(Y_{\mathrm{E}}\right)\left(\mathrm{g}_{\mathrm{p}} \mathrm{g}_{\mathrm{s}}{ }^{-1}\right)$

Theoretical yield $(\%)^{a}$

\section{G80X20}

30

20

4.01

0.69

100

48.32

1.61

0.48

93.68
G60X40

50

17

3.55

0.81

100

46.46

0.93

0.46

90.02

${ }^{a}$ Theoretical yield of ethanol from glucose or xylose is $0.51 \mathrm{~g}_{\mathrm{p}} \mathrm{g}_{\mathrm{s}}^{-1}$; \% theoretical yield is calculated as ethanol yield $\times 100$ divided by 0.51 .

ethanol productivity of $48.32 \mathrm{~g} \mathrm{l}^{-1}$ and $1.61 \mathrm{~g} \mathrm{l}^{-1} \mathrm{~h}^{-1}$, corresponding to theoretical yield of $93.68 \%$. This was in accordance with the studies by Sanchez et al. ${ }^{30}$ which showed that the best ratios of glucose and xylose concentration for high ethanol yields were between 20/5 and 24/1. The fermentation in G20X80 mixture produced a final ethanol titer and ethanol yield of $47.27 \mathrm{~g} \mathrm{l}^{-1}$ and $0.47 \mathrm{~g} \mathrm{~g}^{-1}$, which is slightly lower than that of G80X20, but higher than other cases. The results obtained on high glucose or xylose ration in mixed sugar showed similar pattern with that in the sole sugar fermentation.

\subsection{Inhibitor-supplemented fermentation}

During the pretreatment process, a range of toxic by-products were generated, which inhibited subsequent enzymatic hydrolysis and fermentation. These inhibitors were generally classified into three major groups: weak acid, furans and phenolic compounds. ${ }^{31}$ To better understand the influence of acetic acid, furfural and vanillin, three major inhibitors presented in the hydrolysates on $S$. stipitis ethanol fermentation performance, they were added individually to the medium at various concentrations. As shown in Table 3, S. stipitis MA301 could tolerate up to $3.5 \mathrm{~g} \mathrm{l}^{-1}$ acetic acid, $4.0 \mathrm{~g} \mathrm{l}^{-1}$ furfural and $1.5 \mathrm{~g} \mathrm{l}^{-1}$ vanillin. The ethanol production of $S$. stipitis MA301 in medium containing $1.5 \mathrm{~g} \mathrm{l}^{-1}$ acetic acid, $2.0 \mathrm{~g} \mathrm{l}^{-1}$ furfural and $1.0 \mathrm{~g} \mathrm{l}^{-1}$ vanillin showed little change compared to that of the control. The increase of inhibitor concentration in medium arose the lag phase of cell grow, but caused slight decrease of ethanol titer and ethanol yield. In contrast, the parental could grow only up to $1.5 \mathrm{~g} \mathrm{l}^{-1}$ acetic acid, $2.0 \mathrm{~g} \mathrm{l}^{-1}$ furfural and $1.0 \mathrm{~g} \mathrm{l}^{-1}$ vanillin after a lag period of $48 \mathrm{~h}$. The ethanol production decreased significantly along with the increase of inhibitor concentration, and was completely inhibited in the presence of $2.5 \mathrm{~g} \mathrm{l}^{-1}$ acetic acid, $3.0 \mathrm{~g} \mathrm{l}^{-1}$ furfural and $1.5 \mathrm{~g} \mathrm{l}^{-1}$ vanillin, respectively. The different profiles of cell growth and ethanol production of mutant and parental strain under stress condition indicated the high level inhibitor tolerance of the mutant strain. This might due to the approach of UV mutagenesis following adaption in CTZ.

It was well known that CTZ-resistant mutant exhibited pleiotropic drug resistance (PDR) phenotypes by overexpression of ATP-binding cassette (ABC) transporters. ABC transporters encoded by PDRS/STSl/YDRl, YORl/YRS1, and SNQ2 constituted the majority of drug efflux pumps, responsible for exporting of both xenobiotic compounds such as toxic substances and antibiotics, and endogenous toxic metabolites. Cui et al. ${ }^{32}$ reported that the overexpression of Yorlp in wild type cells of $S$. cerevisiae not only conferred increased resistance to reveromycin A, but also involved in the detoxification of a wide range of the organic anions containing carboxyl group such as acetic acid. In the recent study of investigating the mechanism of $S$. cerevisiae tolerance to $\mathrm{HMF}$ at the genome level revealed that the ATP binding efflux pumps PDR5 and YOR1 were significant expressed during the lag phase in response to the HMF challenge, consequently promoted cellular adaptation and survival by transport either HMF and furfural, or their corresponding alcohols, out of the cell. ${ }^{32}$ From these results we speculated that the induction of PDR5 and YOR1 expression by repeated exposure in high concentration of CTZ might be one of the possible reasons of conferring ethanol fermentable inhibitors tolerance to yeast. The hypothesis would be examined on genome level and the mechanism for vanillin resistance of $S$. stipitis MA301 would be explored in our future study.

\subsection{Continuous fermentation}

In addition to pursing appropriate ethanol producer for ethanol production, ethanol production process optimization was also intensively focused on in order to improve ethanol production from lignocellulosic hydrolysate. A membrane integrated continuous fermentation process could significantly improve lactic acid productivity had been reported in our previous study. ${ }^{33}$ Hence, continuous fermentation with membrane cellrecycle system using $S$. stipitis MA301 for ethanol production from rice straw hydrolysate $(\mathrm{RSH})$ without detoxification was evaluated in present study.

The effect of different dilution rate $(0.03,0.05,0.10$ and 0.15 $\mathrm{h}^{-1}$ ) on sugar consumption rates, residual sugars, ethanol titer and yield was examined in model medium and the result was illustrated in Fig. 3. In the case of dilution rate less than 0.05 $\mathrm{h}^{-1}$, the glucose was consumed completely, and the xylose utilization rate was maintained at a high level of over $97.5 \%$. 


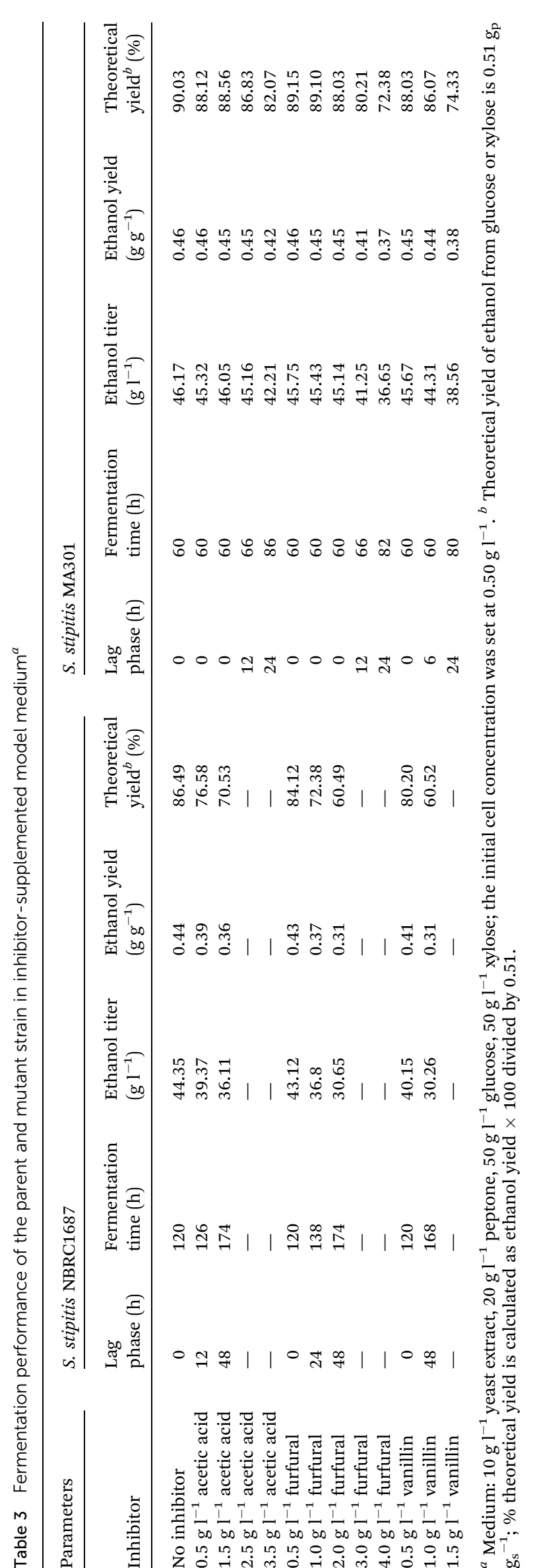

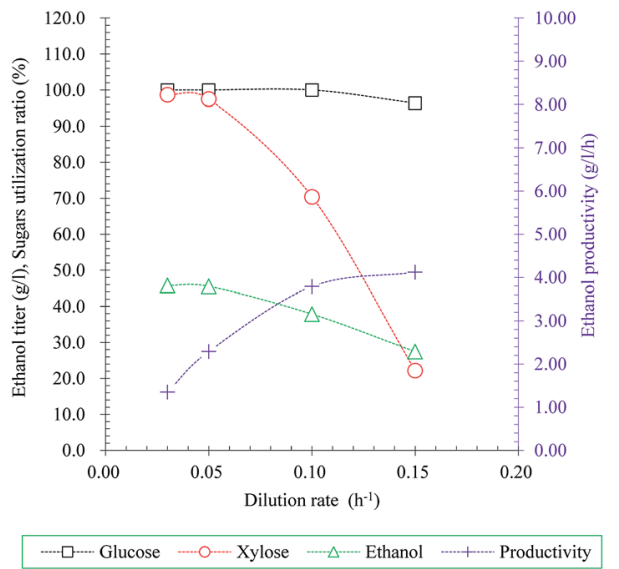

Fig. 3 Effect of dilution rate on ethanol production in continuous fermentation with cell recycling using $S$. stipitis MA301.

However, higher dilution rate caused increase of residual sugars. The consumption rate of glucose and xylose was $96.37 \%$ and $22.19 \%$ at the highest dilution rate, resulted in decrease of ethanol titer, from $45.78 \mathrm{~g} \mathrm{l}^{-1}$ to $27.46 \mathrm{~g} \mathrm{l}^{-1}$ obtained at $0.03 \mathrm{~h}^{-1}$ and $0.15 \mathrm{~h}^{-1}$, respectively. From these observations, the dilution rate $0.05 \mathrm{~h}^{-1}$ was considered as ideal condition for further study.

The continuous culture fermentation with or without membrane cell-recycle system was performed at dilution rate $0.05 \mathrm{~h}^{-1}$ in model medium, and the ethanol production parameters were compared in Table 4 . After $310 \mathrm{~h}$ and $300 \mathrm{~h}$ cultivation, the glucose was completely depleted in both cases, while residual xylose of $16 \mathrm{~g}$ and $217 \mathrm{~g}$ was detected in cell recycling and conventional fermentation system, resulting in xylose conversion rate of $97.6 \%$ and $64.3 \%$, ethanol total production and productivity was $732.1 \mathrm{~g}$ and $2.36 \mathrm{~g} \mathrm{l}^{-1} \mathrm{~h}^{-1}$, $418.2 \mathrm{~g}$ and $1.39 \mathrm{~g} \mathrm{l}^{-1} \mathrm{~h}^{-1}$, respectively. The different ethanol fermentation profiles observed in two types of continuous fermentation could be attributed to the use of cell recycling system, which prevented the cell loss and the improved cell mass accordingly enhanced sugar conversion rate, ethanol titer and yield. In the experiment of ethanol fermentation in RSH medium by membrane cell-recycle system, $38 \mathrm{~g}$ residual xylose, $648 \mathrm{~g}$ ethanol total production and $2.16 \mathrm{~g} \mathrm{l}^{-1} \mathrm{~h}^{-1}$ ethanol productivity was obtained after $300 \mathrm{~h}$ cultivation, which was close to that obtained in model medium. The similar fermentation pattern exhibited in artificial medium and inhibitor present RS hydrolysate could be contributed to the synergistic effect of mutant strain and cell recycling continuous fermentation system. The continuous cultivation might reduce the product inhibition, maintaining cells at a constant physiological state and growth rate, and the cell reuse provided the potential of overcoming the carbon catabolite repression (CCR) effect due to cell acclimation, accordingly led to low residual xylose, high ethanol yield and production rate.

Table 5 listed the recent studies on ethanol fermentation from mixed sugars derived from different lignocelluloses biomass by $S$. stipitis strains. It was notable that the 
Table 4 Comparison of ethanol production in continuous fermentation with or without cell-recycle using S. stipitis MA301 ${ }^{a}$

\begin{tabular}{|c|c|c|c|}
\hline \multirow[b]{3}{*}{ Parameters } & \multicolumn{3}{|l|}{ Mode of fermentation } \\
\hline & \multirow{2}{*}{$\begin{array}{l}\text { Continuous w/ } \\
\text { o cell-recycle system } \\
\text { Run } 1^{b}\end{array}$} & \multicolumn{2}{|c|}{$\begin{array}{l}\text { Continuous w/ } \\
\text { cell-recycle } \\
\text { system }\end{array}$} \\
\hline & & Run $2^{b}$ & Run $3^{c}$ \\
\hline Fermentation time (h) & 300 & 310 & 300 \\
\hline Total feeding glucose $(\mathrm{g})$ & 914.4 & 985.8 & 902.0 \\
\hline Total feeding xylose (g) & 609.6 & 657.2 & 643.0 \\
\hline Residual glucose (g) & 0 & 0 & 0 \\
\hline Residual xylose (g) & 217.0 & 16.0 & 38.0 \\
\hline Residual xylose $\left(\mathrm{g} \mathrm{l}^{-1}\right)$ & 14.5 & 1.03 & 2.5 \\
\hline $\begin{array}{l}\text { Xylose utilization } \\
\text { ratio }(\%)\end{array}$ & 64.3 & 97.57 & 94.09 \\
\hline $\begin{array}{l}\text { Ethanol total } \\
\text { production }(\mathrm{g})\end{array}$ & 418.2 & 732.1 & 648.0 \\
\hline $\begin{array}{l}\text { Ethanol productivity } \\
\left(\mathrm{g} \mathrm{l}^{-1} \mathrm{~h}\right)^{d}\end{array}$ & 1.39 & 2.36 & 2.16 \\
\hline $\begin{array}{l}\text { Ethanol yield }\left(\mathrm{Y}_{\mathrm{E}}\right) \\
\left(\mathrm{g}_{\mathrm{p}} \mathrm{g}_{\mathrm{s}}^{-1}\right)\end{array}$ & 0.32 & 0.45 & 0.43 \\
\hline Theoretical yield (\%) & 62.58 & 87.45 & 84.11 \\
\hline
\end{tabular}

fermentations in all those studies were performed in batch fermentation mode. Among those reports, the maximum ethanol titer of $43.4 \mathrm{~g} \mathrm{l}^{-1}$ and ethanol yield of $0.47 \mathrm{~g} \mathrm{~g}^{-1}$ was obtained in the study of fermentation from non-detoxified corn stalk hydrolysate using a adapted S. stipitis CBS6054. ${ }^{31}$ However, the comparable results obtained in that study were mainly due to the glucose and xylose ratio $(17: 1)$ in hydrolysate, which almost diminished the CCR effect. Moreover, the ethanol productivity of $0.90 \mathrm{~g} \mathrm{l}^{-1} \mathrm{~h}^{-1}$ was almost half of our study. In the study of ethanol fermentation from yellow poplar (DYPH) using S. stipitis KCCM $12009,{ }^{29}$ the glucose and xylose proportion in non-detoxified hydrolysate was $2: 1$, close to our mixed sugar ratio of $1.4: 1$, but the ethanol titer, yield and productivity was more lower than our study. For lignocellulosic ethanol production to be economically viable on an industrial scale, high ethanol titer (above 40-50 $\mathrm{g} \mathrm{l}^{-1}$ ) and high ethanol productivity (over $1 \mathrm{~g} \mathrm{l}^{-1} \mathrm{~h}^{-1}$ ) were required. ${ }^{34}$ By developing high inhibitor tolerant mutant strain and employing membrane integrated continuous fermentation system, $43.2 \mathrm{~g} \mathrm{l}^{-1}$ ethanol titer and $2.16 \mathrm{~g} \mathrm{l}^{-1} \mathrm{~h}^{-1}$ ethanol productivity was achieved, indicating the obtained strain and fermentation process established in this study had great potential for industrial scale bioethanol production in the future.

\section{Conclusions}

We successfully isolated a mutant strain of S. stipitis by strategy of UV mutagenesis following adaptation. The mutant MA301 could tolerate up to $3.5 \mathrm{~g} \mathrm{l}^{-1}$ acetic acid, $4.0 \mathrm{~g} \mathrm{l}^{-1}$ furfural and $1.5 \mathrm{~g} \mathrm{l}^{-1}$ vanillin, and showed excellent ethanol fermentation performance than the parental. Moreover, the cell-recycling continuous fermentation system was first employed in ethanol production from non-detoxified lignocellulosic

Table 5 Summaries of the recent published studies on ethanol production from different lignocellulose hydrolysate using S. stipitis strains ${ }^{a}$

\begin{tabular}{|c|c|c|c|c|c|c|c|c|c|}
\hline \multirow[b]{2}{*}{ Feedstock } & \multirow{2}{*}{$\begin{array}{l}\text { Scheffersomyces } \\
\text { stipitis strains }\end{array}$} & \multicolumn{2}{|c|}{ Initial sugar $\left(\mathrm{g} \mathrm{l}^{-1}\right)$} & \multicolumn{3}{|l|}{ Ethanol } & \multirow{2}{*}{$\begin{array}{l}\text { Fermentation } \\
\text { mode }\end{array}$} & \multirow[b]{2}{*}{ Detoxification } & \multirow[b]{2}{*}{ Ref. } \\
\hline & & Glucose & Xylose & $C\left(\mathrm{~g} \mathrm{l}^{-1}\right)$ & $Y\left(\mathrm{~g} \mathrm{~g}^{-1}\right)$ & $Q_{\mathrm{P}}\left(\mathrm{g} \mathrm{l}^{-1} \mathrm{~h}^{-1}\right)$ & & & \\
\hline Corn cob & NRRL Y-7124 & $35.9^{e}$ & n.r. & 10.4 & 0.34 & 0.11 & Batch & $\mathrm{Y}$ & 35 \\
\hline Wheat straw & NRRL Y-7124 & 6.4 & 45.0 & 12.9 & 0.36 & 0.30 & Batch & $\mathrm{Y}$ & 7 \\
\hline Hardwood SSL & NRRL Y-7124 ${ }^{b}$ & 5.4 & 40.2 & 14.5 & 0.41 & 0.21 & Batch & $\mathrm{N}$ & 20 \\
\hline Water-hyacinth & NRRL Y-7124 & 3.5 & 54.0 & 18.0 & 0.35 & 0.18 & Batch & $\mathrm{Y}$ & 36 \\
\hline Paja brava & CBS 6054 & 2.9 & 19.8 & n.r. & 0.20 & n.r. & Batch & $\mathrm{N}$ & 30 \\
\hline Corn stover & CBS 6054 & $6.3-8.2$ & $24.5-33.5$ & 15.0 & $0.37-0.44$ & 0.21 & Batch & $\mathrm{N}$ & 37 \\
\hline Corn stover & CBS $6054^{b}$ & 40.0 & 25.0 & 25.1 & 0.41 & 0.35 & Batch & $\mathrm{N}$ & 15 \\
\hline Sunflower seed hull & NRRL Y-7124 & $48.0^{e}$ & n.r. & 11.0 & 0.32 & 0.07 & Batch & $\mathrm{Y}$ & 38 \\
\hline Rice straw & BCRC $21777^{b}$ & $3.5-6.4$ & $17.5-26.4$ & 10.3 & 0.44 & 0.25 & Batch & $\mathrm{N}$ & 19 \\
\hline Water-hyacinth & NCIM 3497 & 3.5 & 54 & 18.5 & 0.42 & 0.18 & Batch & $\mathrm{Y}$ & 39 \\
\hline Yellow poplar (DYPH) & КССМ 12009 & 59.5 & 29.7 & 28.7 & 0.48 & 0.40 & Batch & $\mathrm{N}$ & 29 \\
\hline Hazelnut shell & NRRL Y-7124 & $50.0^{e}$ & $36.39^{f}$ & 16.8 & 0.43 & 0.19 & Batch & $\mathrm{Y}$ & 40 \\
\hline Poplar & $\mathrm{GS} 301^{c}$ & 33.0 & 30.0 & 14.0 & 0.24 & 0.10 & Batch & $\mathrm{N}$ & 41 \\
\hline Corn stalk & CBS $6054^{b}$ & 92.34 & 5.4 & 43.4 & 0.47 & 0.90 & Batch & $\mathrm{N}$ & 31 \\
\hline Wheat straw (WH-SF) & DSM 3651 & 23.5 & 6.2 & 12.2 & 0.45 & n.r. & Batch & $\mathrm{N}$ & 10 \\
\hline Rice straw & BCRC $2177^{b}$ & 4.8 & 17.0 & 10.0 & 0.44 & 0.25 & Batch & $\mathrm{Y}$ & 14 \\
\hline Wheat straw & DSM 3651 & 18.5 & 9.23 & 11.6 & 0.41 & n.r. & Batch & $\mathrm{Y}$ & 42 \\
\hline Sugarcane bagasse & NRRL Y-7124 & 5.0 & 50.0 & 7.3 & 0.16 & 0.10 & Batch & $\mathrm{Y}$ & 43 \\
\hline Sugarcane bagasse & NRRL Y-7124 & 5.0 & 50.0 & 15.0 & 0.37 & 0.30 & Batch & $\mathrm{Y}$ & 11 \\
\hline Rice straw & MA301 ${ }^{d}$ & 59.7 & 43.3 & 43.2 & 0.43 & 2.16 & Continuous & $\mathrm{N}$ & This study \\
\hline
\end{tabular}

${ }^{a}$ Note: $C\left(\mathrm{~g} \mathrm{l}^{-1}\right)$, concentration; $Y\left(\mathrm{~g} \mathrm{~g}^{-1}\right)$, yield; $Q_{\mathrm{P}}\left(\mathrm{g} \mathrm{l}^{-1} \mathrm{~h}^{-1}\right)$, productivity; n.r., not reported. ${ }^{b}$ Adapted S. stipitis. ${ }^{c}$ Engineered strain. ${ }^{d} \mathrm{UV}$ mutagenesis and adaptation. ${ }^{e}$ Total reducing sugar. ${ }^{f}$ Xylose, added externally. 
hydrolysate, aiming to reduce the inhibitory influence, overcome CCR effect and improve ethanol productivity. The maximum ethanol titer of $43.2 \mathrm{~g} \mathrm{l}^{-1}$ and productivity of $2.16 \mathrm{~g}$ $\mathrm{l}^{-1} \mathrm{~h}^{-1}$ was achieved, suggesting the process reported was promising for commercial production of bioethanol from lignocelluloses biomass.

\section{Acknowledgements}

This research was financially supported by the following projects: 1. China Scholarship Council (CSC No. 201608210274). 2. National Natural Science Foundation of China (Grant No. 31570055). 3. Youth Science and Technology Foundation of Sichuan Province (Grant No. 2015JQO047). 4. National Key Technology R\&D Program of China (Grant No. 2014BAD02B0603). 5. Special Fund for Agro-scientific Research in the Public Interest (Grant No. 201403019). 6. Fundamental Research Funds for Central Non-profit Scientific Institution (Grant No. Y2017JC39).

\section{Notes and references}

1 J. K. Ko, Y. Um, M. W. Han, K. H. Kim and S. M. Lee, Bioresour. Technol., 2016, 209, 290-296.

2 P. Li, D. Cai, Z. F. Luo, P. Y. Qin, C. J. Chen, Y. Wang, C. W. Zhang, Z. Wang and T. W. Tan, Bioresour. Technol., 2016, 206, 86-92.

3 P. V. Neves, A. P. Pitarelo and L. P. Ramos, Bioresour. Technol., 2016, 208, 184-194.

4 B. C. Saha, N. Qureshi, G. J. Kennedy and M. A. Cotta, Bioresour. Technol., 2015, 190, 182-188.

5 J. K. Ko, Y. Um and S. M. Lee, Bioresour. Technol., 2016, 222, 422-430.

6 K. Ma, Z. Ruan, Z. Shui, Y. Wang, G. Hu and M. He, Bioresour. Technol., 2016, 203, 295-302.

7 J. N. Nigam, J. Biotechnol., 2001, 87, 17-27.

8 S. C. Santos, A. S. de Sousa, S. R. Dionísio, R. Tramontina, R. Ruller, F. M. Squina, C. E. Vaz Rossell, A. C. da Costa and J. L. Ienczak, Bioresour. Technol., 2016, 219, 319-329.

9 B. Zhang, Z. Jia, D. Wang, R. Han, D. Rui, X. Gao, L. Sun and J. Hong, Bioresour. Technol., 2016, 216, 227-237.

10 C. Bellido, S. Bolado, M. Coca, S. Lucas, G. González-Benito and M. T. García-Cubero, Bioresour. Technol., 2011, 102, 10868-10874.

11 D. D. V. Silva, K. J. Dussán, V. Hernández, S. S. D. Silva and C. A. Cardona, Biochem. Eng. J., 2016, 112, 249-257.

12 F. K. Agbogbo and K. S. Wenger, Biotechnol. Lett., 2006, 28, 2065-2069.

13 M. Liang, M. H. Kim, Q. P. He and J. Wang, J. Biosci. Bioeng., 2013, 116, 319-326.

14 T. H. Lin, C. F. Huang, G. L. Guo, W. S. Hwang and S. L. Huang, Bioresour. Technol., 2012, 116, 314-319.

15 F. K. Agbogbo, F. D. Haagebsen, D. Milam and K. S. Wenger, Appl. Biochem. Biotechnol., 2008, 145, 145-153.

16 P. Chandrakant and V. S. Bisaria, Crit. Rev. Biotechnol., 1998, 18, 295-331.
17 J. P. Delgenes, R. Moletta and J. M. Navarro, Biotechnol. Lett., 1986, 8, 897-900.

18 D. R. J. Grootjen, R. G. J. M. van der Lans, K. Ch and A. M. Luyben, Enzyme Microb. Technol., 1990, 12, 20-23.

19 C. F. Huang, T. H. Lin, G. L. Guo and H. Wensong, Bioresour. Technol., 2009, 100, 3914-3920.

20 J. N. Nigam, J. Appl. Microbiol., 2001, 90, 208-215.

21 T. Watanabe, I. Watanabe, M. Yamamoto, A. Ando and T. Nakamura, Bioresour. Technol., 2011, 102, 1844-1848.

22 P. K. Bajwa, T. Shireen, F. D'Aoust, D. Pinel, V. J. J. Martin, J. T. Trevors and H. Lee, Biotechnol. Bioeng., 2009, 104, 892-900.

23 E. Casey, M. Sedlak, N. W. Y. Ho and N. S. Mosier, FEMS Yeast Res., 2010, 10, 385-393.

24 T. Hasunuma, T. Sanda, R. Yamada, K. Yoshimura, J. Ishii and A. Kondo, Microb. Cell Fact., 2011, 10, 2.

25 H. W. Wisselink, M. J. Toirkens, Q. Wu, J. T. Pronk and A. J. A. V. Maris, Appl. Environ. Microbiol., 2008, 75, 907-914.

26 S. R. Hughes, W. R. Gibbons, S. S. Bang, R. Pinkelman, K. M. Bischoff, P. J. Slininger, N. Qureshi, C. P. Kurtzman, S. Liu and B. C. Saha, J. Ind. Microbiol. Biotechnol., 2012, 39, 163-173.

27 H. Mizoguchi, T. Yamauchi, M. Watanabe, H. Yamanaka, A. Nishimura and H. Hanamoto, J. Biosci. Bioeng., 2002, 93, 221-227.

28 K. Ma, G. Hu, L. Pan, Z. Wang, Y. Zhou, Y. Wang, Z. Ruan and M. He, Bioresour. Technol., 2016, 219, 114-122.

29 D. H. Cho, S. J. Shin, Y. Bae, C. Park and Y. H. Kim, Bioresour. Technol., 2010, 101, 4947-4951.

30 G. Sanchez, L. Pilcher, C. Roslander, T. Modig, M. Galbe and G. Liden, Bioresour. Technol., 2004, 93, 249-256.

31 X. Yang, S. Zhang, Z. Zhuang, M. Xun and T. Shen, Bioresour. Technol., 2011, 102, 7840-7844.

32 Z. Cui, D. Hirata, E. Tsuchiya, H. Osada and T. Miyakawa, J. Biol. Chem., 1996, 271, 14712-14716.

33 M. Ma and Z. L. Liu, BMC Genomics, 2010, 11, 660.

34 C. Fan, K. Qi, X. X. Xia and J. J. Zhong, Bioresour. Technol., 2013, 136, 309-315.

35 N. Eken-Saraçoglu and Y. Arslan, Biotechnol. Lett., 2000, 22, 855-858.

36 J. N. Nigam, J. Biotechnol., 2002, 97, 107-116.

37 F. K. Agbogbo and K. S. Wenger, J. Ind. Microbiol. Biotechnol., 2007, 34, 723-727.

38 M. Telli-Okur and N. Eken-Saraçoğlu, Bioresour. Technol., 2008, 99, 2162-2169.

39 A. Kumar, L. K. Singh and S. Ghosh, Bioresour. Technol., 2009, 100, 3293-3297.

40 Y. Arslan and N. Eken-Saraçoğlu, Bioresour. Technol., 2010, 101, 8664-8670.

41 P. K. Bajwa, C. Phaenark, N. Grant, X. Zhang, M. Paice, V. J. J. Martin, J. T. Trevors and H. Lee, Bioresour. Technol., 2011, 102, 9965-9969.

42 C. Bellido, G. Gonzálezbenito, M. Coca, S. Lucas and M. TGarcía-Cubero, Bioresour. Technol., 2013, 133, 51-58.

43 K. J. Dussán, D. D. V. Silva, V. H. Perez and S. S. D. Silva, Renewable Energy, 2016, 87, 703-710. 